\title{
UNIVERSIDAD Y RESPONSABILIDAD SOCIAL
}

María Julia Sierra Moncayo*

RESUMEN: En este ensayo se dilucida pretende explicar la naturaleza de la crisis que enfrentan las universidades de nuestro tiempo. Se explican algunas transformaciones, se analizan las relaciones conflictivas entre la universidad y la sociedad, y se describen proyectos que rompen con el sentido y los valores fundamentales que la han caracterizado desde su fundación. Se describe el fondo permanente que la particulariza y que ha defendido durante cerca de siete siglos, y que es lo que le ha permitido al mismo tiempo permanecer, cambiar y ser un actor primordial en la construcción del hombre y la sociedad del futuro. Se ubica al ITAM en esta perspectiva.

\section{wos \\ UNIVERSITY AND SOCIAL RESPONSIBLITY}

ABSTRACT: In this article, we will explain the type of crisis facing universities today. In particular, we will address some changes that they have suffered through and also analyze the troublesome relationship between University and society. Furthermore, we will describe projects that torn it away from its philosophy and fundamental values of its founding days. We will also describe its foundation which it has defended for more than seven centuries allowing it to persist, adapt, and play a primary role in the construction of man and the society of the future. We will look at ITAM in this perspective.

PALABRAS CLAVE: Estudios generales, libertad, autonomía, formación humana, cultura, comunidad, conciencia crítica y responsabilidad social.

Key words: University, general studies, freedom, autonomy, human formation, culture, community, critical conscience, and social responsibility.

* Departamento Académico de Estudios Generales, ITAM. 
RECEPCIÓN: 1 de diciembre de 2015.

APROBACIÓN: 8 de junio de 2016.

Estudios 118, vol. XIV, otoño 2016. 


\section{UNIVERSIDAD Y RESPONSABILIDAD SOCIAL}

El dios del mar del Norte dijo: ¿Cómo podré hablar del mar con la rana si no ha salido de su charca?

¿Cómo podré hablar del hielo con el pájaro de estio si está retenido en su estación? ¿Cómo podré hablar con el sabio acerca de la Vida, si es prisionero de su doctrina?

CHUANG TSE ${ }^{1}$

La Universidad como inteligencia crítica de la sociedad, como recinto de humanidad y de dignidad, la Universidad que sirve inmensamente a la sociedad con la generación del saber, con la trasmisión y proyección de la verdad [...] que no es servil a los grupos de poderes políticos o económicos, la Universidad que mantiene su libertad y autonomía y, desde si misma conoce, juzga y aporta soluciones a los problemas sociales, está amenazada y acosada por las imposiciones reinantes.

CARLOS DE LA ISLA ${ }^{2}$

\section{Introducción}

Como en toda época de grandes mutaciones, aparecen diversas propuestas que buscan transformar a la universidad a fin de capacitar a las generaciones presentes para el mañana. Así, en las primeras décadas del siglo XXI, las múltiples alternativas se pueden clasificar en dos categorías. Las primeras, las más aceptadas, son las que buscan que la universidad se adapte a las necesidades sociales de la globalización y el mercado. Las segundas procuran que las universidades se conviertan en agentes de cambio para edificar

${ }^{1}$ Citado en José Ramón Benito, "Universidad y Filosofía”, Estudios núm. 1, otoño de 1984, en $<$ http://biblioteca.itam.mx/estudios/estudio/estudio01/sec_36.html $>$, consultado el $12 \mathrm{de}$ septiembre de 2014.

${ }^{2}$ Carlos de la Isla, "Ética y universidad", en Reflexiones sobre la responsabilidad ética de la universidad, Problemas de la Civilización Contemporánea II, 2014, México, ITAM, p. 14. 
al hombre y a la sociedad del futuro. Las primeras se consideran realistas, pero solo ven el presente, y, como dice Chuang Tse, están prisioneras de las doctrinas imperantes. Las segundas, consideradas por muchos como utópicas, se fundamentan en una antropología que considera al hombre como ser libre, crítico, responsable socialmente. Por esto, como afirma De la Isla, la universidad está en vilo, en peligro. En el presente ensayo se pretende explicar estas posturas y la naturaleza de la crisis que enfrentan las universidades de nuestro tiempo.

\section{Universidad y Estudios Generales}

Marc Bloch cita en Introducción a la historia ${ }^{3}$ un viejo proverbio árabe: "los hombres se parecen más a su tiempo que a sus padres", y más adelante agrega: "Hemos aprendido que el hombre ha cambiado mucho: en su espíritu y, sin duda, hasta en los más delicados mecanismos de su cuerpo. ¿Cómo había de ser de otro modo? [...] Pero a pesar de todo es menester que exista en la naturaleza humana y en las sociedades un fondo permanente, sin el cual ni aun las palabras hombre y sociedad querrían decir nada".

La universidad es una de las instituciones más antiguas en la historia de Occidente. Sus orígenes se sitúan a finales del siglo XII y principios del XIII. Esta institución ha evolucionado a lo largo de los siglos, ha sufrido graves crisis que han puesto en riesgo su existencia. Para citar algunas, podríamos hablar de su férrea defensa de la autonomía y de la libertad de pensamiento frente a los poderes políticos, económicos e ideológicos; los cambios en las concepciones del hombre y del mundo; las grandes transformaciones histórico-sociales, que muchas veces la envolvieron en torbellinos de violencia y represión; los avances científicos y técnicos y sus implicaciones, tanto para el conocimiento como por su aplicación. A pesar de todo, en las primeras décadas del siglo XXI la universidad sigue aquí, enfrenta nuevos retos y busca redefinirse. Precisamente por esto cabe preguntarse acerca de ese fondo permanente que

${ }^{3}$ Marc Bloch, Introducción a la historia, 1987, México, FCE, pp. 34 y 43. 
nos permite seguir hablando de ella como universidad ¿En qué consiste su misión fundamental? ¿Qué la define como universidad? ¿Cuál es su característica esencial?

La permanencia de este fondo no significa que no pueda reinterpretarse y ser recreado en épocas de cambios fundamentales. Es lo que ha venido ocurriendo desde que se fundaron las universidades. Se trata de volver a los orígenes para inspirarse en ellos en esa relación del pasado con el futuro. Esta reflexión original, crítica y creativa es la que ha dado solidez a la universidad.

Antes del descubrimiento y la conquista de América, en el siglo XV, las corrientes humanistas recorrieron Europa y cambiaron las concepciones del hombre y el mundo en la transición de la Edad Media al Renacimiento. Por la influencia de Erasmo de Rotterdam y personalidades de la talla de Dante Alighieri, Tomás Moro y Pico della Mirandola, se volvió a la lectura de los clásicos griegos y latinos en busca de inspiración para ofrecer nuevas explicaciones y orientaciones para la acción. Las universidades no escaparon a estas corrientes y se recrearon. Para nosotros es particularmente significativa la transformación de las universidades españolas desde finales del siglo XI a principios del siglo XVI. Los universitarios españoles fueron el único grupo de la Europa moderna que se planteó la legitimidad de las conquistas. Fueron intelectuales íntegros que no justificaron con argumentos tradicionales estos hechos y además contribuyeron de manera importante a la concepción actual del derecho internacional y de los derechos humanos.

El cardenal Francisco Jiménez de Cisneros (1436-1517) fundó la Universidad de Alcalá de Henares (1499), que se convirtió en uno de los grandes centros del humanismo cristiano, teniendo como eje el studium generale y la teología. Cisneros determinó que la universidad no debía ser exclusivamente un centro erudito de saber y fomentó su participación activa en la sociedad y en la política. En ella enseñaron y estudiaron personajes tan importantes como Antonio de Nebrija, Juan Ginés de Sepúlveda, Ignacio de Loyola, Domingo de Soto, Francisco Suárez, San Juan de la Cruz, Mateo Alemán, Lope de Vega, Francisco de Quevedo y Villegas, Pedro Calderón de la Barca y Melchor Gaspar de Jovellanos, entre muchos otros. 
La Universidad de Salamanca (1218), una de las más antiguas de Europa, se reformó por la influencia de sus humanistas, entre los que se cuentan Francisco de Vitoria, Martín de Azpilcueta, Fray Luis de León, Francisco Suárez, Melchor Cano, Luis de Molina, Luis de Alcalá y Bartolomé de Medina. Ellos renovaron la teología, sentaron las bases tanto del derecho de gentes, antecedente del actual derecho internacional así como de la ciencia moderna de la economía. Participaron activamente en el Concilio de Trento (1545 y 1563). Sus matemáticos estudiaron la reforma al calendario y propusieron la solución que finalmente se estableció. En este tiempo, la universidad contó con las primeras alumnas, Beatriz Galindo (1465-1535) y Lucía de Medrano (1484-1527), que además fue la primera mujer en dar clases en la universidad. Gracias a la participación de todos ellos, las autoridades promulgaron leyes que moderaron la crueldad de la conquista de América.

Desde finales del siglo XIX y en la primera mitad del siglo XX, en Europa y América Latina apareció un movimiento contrario al cientificismo positivista, el pragmatismo y la especialización en la educación superior, lo que dio origen al llamado movimiento de los estudios generales $^{4}$ en las universidades europeas, estadounidenses y latinoamericanas.

José Ortega y Gasset y Robert Hutchins fueron las principales figuras intelectuales del movimiento de los Estudios Generales, sin menospreciar el papel que cumplieron otros pensadores estadounidenses como Stringfellow Barr, Scott Buchanan y Alexander Meiklejohn, o latinoamericanos, como Ángel Quintero Alfaro y Ernesto Mayz Vallenilla. ${ }^{5}$

A estos nombres deben agregarse los de importantes figuras mexicanas como José Vasconcelos, Daniel Cosío Villegas, Alfonso Caso, Miguel Palacios Macedo, Consuelo Meyer y muchos otros creadores de instituciones en el México posrevolucionario. Estos movimientos fomentaban el pensamiento crítico y la creatividad de los estudiantes

${ }^{4}$ Jorge Rodríguez Beruff, "Estudios Generales en los estudios universitarios contemporáneos”, Estudios 97, vol. IX, verano de 2011, pp. 19-38.

${ }^{5}$ Loc. cit. 
gracias a una formación humanística y cultural como parte esencial del currículo profesional. A continuación se exponen las conclusiones de algunos de los principales autores de estas reformas universitarias y sus sugerencias para renovarlas creativamente.

En Inglaterra, el cardenal John Henry Newman ${ }^{6}$ (1801-1890), considerado uno de los iniciadores, decía que la universidad es la comunidad de profesores y estudiantes que se reúnen a pensar y conocer. Es un lugar que enseña el saber universal. ${ }^{7}$

El español José Ortega y Gasset ${ }^{8}(1883-1955)$, quien influyó notablemente en América Latina y Estados Unidos, explicó que toda reforma busca no corregir los abusos, sino crear nuevos usos. Afirmaba que la misión de la universidad consiste en la transmisión de la cultura, la enseñanza de las profesiones y la investigación científica y la formación de nuevos investigadores, en ese orden de importancia. Definió a la cultura como:

El sistema de ideas vivas desde las cuales un tiempo vive [...] No podemos vivir humanamente sin ideas. De ellas depende lo que hagamos, y vivir no es sino hacer esto o lo otro. Así dice el viejísimo libro de la India: "Nuestros actos siguen a nuestros pensamientos como la rueda del carro sigue a la pezuña del buey". Por eso somos nuestras ideas. ${ }^{9}$

Robert Hutchins ${ }^{10}$ (1899-1977), en la Universidad de Chicago, Estados Unidos, afirmaba que la finalidad de la educación no es, como

${ }^{6}$ John Henry Newman, estudió en el Trinity College de Oxford, fue un miembro destacado del movimiento de Oxford que buscaba recuperar las tradiciones sustantivas de la Iglesia anglicana y fundó la Universidad Católica de Dublín. Sus reflexiones sobre la universidad siguen teniendo gran influencia.

${ }^{7}$ Cfr. John Henry Newman, "Idea de la universidad", en Naturaleza y fin de la educación universitaria, 1946, Madrid, Colecciones y Publicaciones Españolas, p. 48.

${ }^{8}$ José Ortega y Gasset fue un filósofo y ensayista español, exponente principal de la teoría del perspectivismo y de la razón vital e histórica. Ejerció gran influencia en la filosofía iberoamericana del siglo XX. Sus reflexiones sobre la universidad contribuyeron a muchas de las reformas universitarias del continente americano.

${ }^{9}$ Cfr. José, Ortega y Gasset, Misión de la universidad, en <http://www.esi2.us.es/ fabio/ mision.pdf>, p. 4, consultado el 12 de agosto de 2014.

${ }^{10}$ Robert Maynard Hutchins fue un filósofo de la educación, decano de la Escuela de Leyes de Yale, canciller y presidente de la Universidad de Chicago, donde inició su reforma. Junto con Mortimer Adler publicó los 54 volúmenes de los Great Books of the Western World. 
frecuentemente se piensa, preparar a los jóvenes para ganarse la vida, sino formar ciudadanos responsables. ${ }^{11}$ Por ello, "solo una educación concebida como crecimiento moral, intelectual, estético y espiritual puede realizar esos objetivos". ${ }^{12}$ Sobre la especialización profesional, decía que la educación también debía ser útil y servir a las necesidades de las personas y de las sociedades y se preguntaba cuáles serían esas necesidades reales que la educación debería resolver. A lo que contestaba: formar ciudadanos libres y responsables en sociedades democráticas. $^{13}$

El influyente profesor de historia de las grandes ideas de Occidente de la Universidad de Estrasburgo, Georges Gusdorf ${ }^{14}$ (1912-2000), afirmaba que la universidad es:

Una utopía, un sueño que, sin duda alguna, jamás llegará a encarnarse sobre la faz de la tierra. Gracias a ese incumplimiento, engendra una auténtica riqueza que moviliza más energías y suscita proezas que los planes realistas no logran; porque una vez realizados, se olvidan. La principal tarea de la Universidad, la que le imprime su carácter más original, es la de humanizar al hombre. ${ }^{15}$

Por eso, en cierto sentido, la universidad es inútil y costosa. No es necesaria para satisfacer las necesidades sociales de subsistencia. Requiere ocio, indispensable para la reflexión, el pensamiento y la creación de cultura. Cualquier otra institución puede capacitar para el ejercicio técnico y profesional. Asimismo, la investigación científica no es una

Es considerado uno de los impulsores, junto con Ortega y Gasset, y otros pensadores estadounidenses y latinoamericanos, del movimiento de los estudios generales.

${ }^{11}$ Cfr. Robert, Hutchins, Educación y universidad en utopía, 1968, Buenos Aires, EUDEBA, pp. 9-65.

${ }^{12}$ Ibid., p. 19.

${ }^{13}$ Ibid., p. 57.

${ }^{14}$ Georges Gusdorf fue un filósofo francés que hizo importantes contribuciones a la historia de las ideas. Estuvo prisionero en un campo de concentración nazi. Fue profesor en la Universidad de Estrasburgo y de la Universidad de Quebec. Fue maestro de Althuser y de Foucault.

${ }^{15}$ Georges Gusdorf, L’Université en question, 1964, París, Les Éditions Payot, p. 14, en Chicoutimi, $<$ http://classiques.uqac.ca/contemporains/gusdorf_georges/universite_en_question/ universite_en_question.html>, consultado el 10 de octubre de 2014. 
prerrogativa exclusiva de la universidad, sino que hay otras instancias que la realizan. Sin embargo, cabría preguntarse por qué todos los países de Occidente, sin excepción, tienen universidades. ${ }^{16}$ La universidad, como escuela de humanidad, no es solamente un conjunto de saberes, sino un estilo de vida, una comunidad dialogante. ${ }^{17}$

En síntesis, siguiendo a Gusdorf, "la universidad presupone la comunidad humana en la investigación, la difusión y la defensa de los valores del pensamiento. Igualmente requiere la unidad del conocimiento. La palabra 'universidad' no puede aplicarse a un instituto aislado o una escuela superior, porque es la única Escuela Universal [...] Perpetúa el ideal medieval de studium generale y de universitas scientiarum". ${ }^{18}$ Más adelante explica que, de acuerdo con la más antigua tradición occidental, "la universidad es, en su conjunto, la depositaria y garante de la unidad del saber. Universidad significa que el saber forma un todo, que la coherencia y la convergencia de las disciplinas es un bien, la especialización abusiva es una forma de alienación". ${ }^{19}$ Por esta razón, las distintas facultades o departamentos que la constituyen permanecen unidos y no han buscado separarse de ella. Por último, "la Universidad se encuentra presente solamente cuando la enseñanza y la investigación tienen una cita con la libertad, indispensable para el desarrollo humano". ${ }^{20}$

De esta manera, para los autores mencionados no hay universidad sin una comunidad que dialoga y sin estudios generales o universitas scientiarum, unión de saberes que permiten humanizar al hombre. Desde su fundación, el ITAM, heredero de estos movimientos, ha contribuido a la formación integral de sus alumnos, educándolos en el pensamiento crítico con un profundo sentido ético y serio compromiso de responsabilidad social.

\footnotetext{
${ }^{16}$ Ibid., p.73.

${ }^{17}$ Ibid., p. 98.

${ }^{18}$ Ibid., pp. 77-88.

${ }^{19}$ Ibid., p. 137.

${ }^{20}$ Ibid., p. 140.
} 
Uno de sus rectores, Javier Beristáin ${ }^{21}$ (1944-2009) solía decir, citando a John Stuart Mill (1806-1873):

Los hombres son hombres antes que profesionistas y si con la educación los hacemos capaces y sensatos serán abogados o médicos capaces y sensatos. Por naturaleza el hombre quiere conocer y aspira a alcanzar la sabiduría. Los egresados deben llevarse de la Universidad, no solo el conocimiento profesional, sino también aquello que rija el uso de ese conocimiento e ilumine con la cultura universal los aspectos técnicos de su especialidad. ${ }^{22}$

Como instituciones universitarias su contribución se hace y hará mediante la formación humana y profesional, la investigación científica y la extensión cultural. El compromiso vital de toda institución universitaria seguirá siendo con la búsqueda de la verdad. Descubrir el conocimiento verdadero es la característica esencial de la Universidad y es tarea que le es obligatoria [...] La segunda gran tarea propia de la Universidad es la docencia, que ofrece los medios para la formación integral de la persona. Esta compete principalmente a las universidades. En ello estriba su ventaja comparativa: la Universidad se ocupa de enseñar visiones alternativas del mundo, de la sociedad y de la persona, hace pensar y facilitar la creación de ideas, su expresión y defensa, así como su aplicación sabia, comprometida y crítica a la creación, orientación y dirección de instituciones. ${ }^{23}$

A esa importantísima misión que tiene la Universidad de formar hombres cultos y simultáneamente profesionales competentes debemos agregar la de actuar como agente de cambio social. Creemos que de las universidades surgirán los hombres y las ideas que iluminarán el sentido del desarrollo del mundo contemporáneo. Por ello, la Universidad no puede permanecer marginada, insensible a las necesidades y demandas cambiantes de la sociedad, ni mantenerse dirigida a satisfacer los intereses

${ }^{21}$ Javier Beristáin Iturbide (1944-2009), economista, educador y funcionario público mexicano. Fue rector del ITAM y miembro de su Junta de Gobierno.

${ }^{22}$ Javier Beristáin, "Misión de la universidad", discurso leído en la ceremonia de inicio de cursos del ITAM en septiembre de 1973. Recopilado en Javier Beristáin, ¿Renacimiento o metamorfosis? La gestación del Programa Universitario del ITAM, 1983, México, ITAM, pp. 6-12.

${ }^{23}$ Javier Beristáin, "La búsqueda de la Verdad y del bienestar social, inseparables en la misión del ITAM", mensaje leído el 9 de marzo de 1987 en la ceremonia conmemorativa del XL aniversario del ITAM. Publicado en Memoria de la ceremonia conmemorativa del XL aniversario del ITAM, 1987, México, ITAM, pp. 33-40. 
de una elite profesional relativamente limitada, la cual prefiere conservar antes que cambiar. La Universidad, y esto lo subrayamos, tiene que intervenir en la actualidad como tal, como Universidad, es decir, no solo a través de los esfuerzos aislados de algunos de sus elementos, por valiosos y valerosos que sean, sino mediante la labor conjunta e integradora de esfuerzos que la comunidad universitaria debe lograr. La actuación de la Universidad debe ser serena, reflexiva y objetiva, resultado de la discusión libre, científica, sin prejuzgar sobre los problemas, para aportar soluciones posibles y desinteresadas. ${ }^{24}$

Algunos de sus grandes profesores, como Carlos de la Isla y José Ramón Benito, nos dicen lo que debe ser la universidad en general y el ITAM en particular.

Carlos de la Isla ${ }^{25}$ recuerda que la universidad debe ser la conciencia crítica de la sociedad, lo que significa que su misión consiste en lo siguiente:

Pensar (la investigación no es otra cosa que pensar al mundo y a nosotros en el mundo), enseñar a pensar (y esta es la esencia de la educación universitaria), transmitir y acrecentar el pensamiento (en esto consiste la extensión de la cultura). La universidad como conciencia crítica de la sociedad debe conocer la realidad social en su totalidad, esta es la materia de su pensamiento; pero esta acción reflexiva sobre la sociedad no termina en el pensamiento, ha de juzgarla y con actitud crítica, denunciar, anunciar, inventar. ${ }^{26}$

Además de cultivar con pasión el amor y el gusto por el saber, se debe buscar que la verdad se convierta en vida y libertad. Este es el deber

${ }^{24}$ Beristáin, "Misión de la universidad", pp. 11-12.

${ }^{25}$ Carlos de la Isla Veraza, filósofo y educador mexicano, profesor emérito del ITAM en el Departamento Académico de Estudios Generales. Este Departamento en particular y todo el ITAM en general le deben parte de su identidad gracias a sus orientaciones, sus escritos y su labor docente.

${ }^{26}$ Carlos de la Isla, "Universidad: conciencia crítica", en Reflexiones sobre la Universidad como conciencia crítica de la sociedad, Problemas de la Civilización Contemporánea I, 2012, México, ITAM, p. 8; véase también, Estudios, núm. 25, vol. VIII, verano de 1991, pp. 69-76. 
ético que tiene la universidad, porque de la verdad surge la pasión por la justicia. En esto consiste la responsabilidad social que es el deber de todo universitario. ${ }^{27}$

Una Universidad forma hábitos y actitudes justas si es una Universidad donde gobierna la razón y se vive la justicia: un lugar en el que los estudiantes puedan encontrar los medios y oportunidades convenientes para su desarrollo personal en los planos intelectual, estético, espiritual y moral. Donde los profesores investigan, generan y comunican conocimientos, muestran caminos deseables con sus propias vidas, comunican a sus alumnos el placer de saber [...] la Universidad buena y justa es la que enseña la justicia, siendo justa. Y es buena y justa cuando cada quien hace muy bien lo que le corresponde. También es deber formativo de la Universidad beneficiar a la comunidad circundante y a toda la sociedad con sus aportaciones académicas e intelectuales sobre los problemas vigentes, ampliando su influencia social. ${ }^{28}$

José Ramón Benito, ${ }^{29}$ en su artículo “Latinoamérica y la universidad”, dice que la universidad es el lugar del pensamiento:

Pensar en la Universidad significa pensar y amar al hombre y a la sociedad de la que la Universidad ha de ser faro y fortaleza; significa pensar desde el hombre y desde la sociedad, no para reproducir los patrones y las demandas ciegas que se les imponen y hacer de la Universidad un dócil instrumento al servicio de fuerzas deshumanizantes y destructoras. ${ }^{30}$

${ }^{27}$ Carlos, de la Isla, "Ética y universidad", en Reflexiones sobre la responsabilidad ética de la universidad, Problemas de la Civilización Contemporánea II, 2012, México, ITAM, p. 14.

${ }^{28}$ Loc. cit.

${ }^{29}$ José Ramón Benito Alzaga, filósofo y educador mexicano. Profesor emérito del ITAM, fue Jefe del Departamento Académico de Estudios Generales y actualmente es Director de la División Académica de Estudios Generales y Estudios Internacionales. El ITAM y el Departamento de Estudios Generales tienen una deuda con su pensamiento y dedicación a la solidez del Instituto.

${ }^{30}$ José Ramón Benito, “Latinoamérica y la Universidad”, Estudios, núm. 26, otoño de 1991, $<$ http://biblioteca.itam.mx/estudios/estudio/letras26/texto3/sec_1.html $>$. 
En la universidad se enseña el conocimiento universal, los distintos saberes se integran y estructuran alrededor de la búsqueda de sentido del proyecto humano. Esto es precisamente lo que les da unidad.

La Universidad es, por lo tanto, relación o comunidad de profesores y estudiantes, un lugar de conocimiento entendido como parte del hombre y de su actividad intelectual [...] La inteligencia como apropiación de la verdad necesita un desarrollo, un progreso que tiene que irse manteniendo en forma viva, de manera que esté siempre abierto en un sentido dinámico, en un sentido de crecimiento y de renovación, de revisión permanente [...] En su carácter de relación, de convivencia, significa una verdad dialogada. Una búsqueda y al mismo tiempo una posición, un alcance, un logro de la verdad en la comunicación, porque el diálogo es a la vez pensamiento y palabra [...] Yo creo que puede haber una verdad propia, un sentido propio de la verdad, pero yo creo que para que la verdad sea verdad para mí, la tengo que hacer mía. Y este hacer mía la verdad requiere de la verdad para todos, de la verdad en si. ${ }^{31}$

El papel activo, creador de la universidad en relación con la sociedad se funda en el diálogo:

Es en la sociedad, por la sociedad y para la sociedad, que los hombres se han reunido en esta búsqueda de la verdad; ese para la sociedad tiene siempre esta dinámica de revisión crítica [...] Las demandas sociales tienen que ser críticamente rectificadas, analizadas, discriminadas, dentro de la propia comunidad universitaria para que tengan, tanto esta como la sociedad mutuamente, la función que cada una de ellas ha de cumplir y la que recíprocamente esperan la una de la otra. ${ }^{32}$

\section{Transformación de los objetivos de la universidad}

A finales del siglo XX y principios del XXI, los fenómenos de la posmodernidad cultural y la globalización económica han transformado las maneras de ver al mundo y al hombre. En esta transición encontramos

${ }^{31}$ José Ramón Benito, "Universidad y filosofía”, Estudios núm. 1, otoño de 1984, <http:// biblioteca.itam.mx/estudios/estudio/estudio01/sec_36.html>.

${ }^{32}$ Loc. cit. 
dos tendencias. La primera busca que la universidad se subordine a los intereses del mercado y la segunda propugna volver a reflexionar sobre el sentido humano de los estudios generales para hacerla capaz de pensar los problemas sociales, científicos, ambientales, entre los más significativos que ponen en riesgo la existencia de nuestra especie y las posibilidades de constitución de una humanidad plural, íntegra, justa y solidaria.

\section{Estados Unidos}

En la primera tendencia, muchos autores, como Robert Lapiner (1954), ${ }^{33}$ piensan que la tarea de las universidades es capacitar al capital humano para dirigir el mundo.

Para que la educación superior responda a la etapa transnacional de la organización industrial e intelectual dependerá de tres factores: 1) Adaptación a las estructuras internacionales existentes para la actividad trasnacional; 2) mayor acercamiento de la industria y la academia, no solo en áreas de posibilidades directas de colaboración (investigación comercialización de descubrimientos científicos, entrenamiento), sino en una definición en general de misiones y estructuras administrativas; y 3) desarrollo de oportunidades progresivamente incrementadas para la movilidad, con énfasis particular en el acceso y uso de tecnologías de telecomunicaciones educativas y las relacionadas con las necesidades empresariales e industriales. ${ }^{34}$

\section{América Latina y México}

De acuerdo con lo propuesto por Lapiner, en América Latina cada vez hay más empresas que crean a sus propias "universidades". En un

${ }^{33}$ Robert S. Lapiner, pedagogo estadounidense. Fue decano de educación continua de la Universidad de California, Los Ángeles, y es el actual decano y rector de Educación Continua y Estudios Profesionales de la Universidad de Nueva York.

${ }^{34}$ Robert Lapiner, Definiciones y retos en la educación superior transnacional, en $<$ http://publicaciones.anuies.mx/revista/90/1/5/es/definiciones-y-retos-en-la-educacion-superior-trasnacional>, consultado el 22 de septiembre de 2014. 
artículo de $\mathrm{CNN}^{35}$ se expone que las compañías han adoptado este medio de capacitación para responder a la falta de personal calificado. El sistema se está extendiendo en toda la región, aunque Brasil y México concentran más del 40\% de estas instituciones.

Entre las empresas que en México tienen “universidades" está Volkswagen, ${ }^{36}$ con el Instituto para Formación y Desarrollo Volkswagen, S.C. que, de acuerdo con su página en internet, nació como una sociedad civil en enero de 1996 para apoyar a la sociedad y a la comunidad empresarial en el desarrollo de su personal, con la finalidad de capacitarlo para alcanzar niveles de competitividad y mantener sus ventajas en los mercados.

Otra compañía que adopta estos nuevos modelos de capacitación es Liverpool, una de las tiendas departamentales más grandes del país. En 2000, fundó la Universidad Virtual Liverpool (UVL), con la finalidad de "alinear los objetivos de la empresa con las capacidades y habilidades de sus 47000 empleados". ${ }^{37}$ En 2013 contaba con 1800 egresados. En ese año los graduados estaban distribuidos de la siguiente manera: $6 \%$ de bachillerato, $2 \%$ de carreras técnicas, $49 \%$ de licenciaturas, $22 \%$ de maestrías y $21 \%$ de educación básica. ${ }^{38}$

En su página de internet ${ }^{39}$ puede leerse que nació

como respuesta a la búsqueda de complementar los proyectos de capacitación, así como dar un valor agregado en materia de educación y formación a los integrantes de la familia Liverpool [...] se materializa por

${ }^{35}$ Cfr. CNN, Expansión, Gabriel Sama, $1^{\circ}$ de diciembre de 2013, en: < http://www.cnnexpansion. com/expansion/2013/11/25/te-falta-talento-haz-tu-propia-escuela>.

${ }^{36}$ Empresa actualmente sumida en un escándalo ético y penal por haber introducido en algunos de sus modelos un software para pasar las pruebas de emisión de contaminantes, según informó el Centro de Emisiones de la Universidad de Virginia, después de una investigación realizada a petición del Internacional Council of Clean Transportion, una organización no gubernamental estadounidense. Véase, "Cómo llegó Volkswagen a una de las peores crisis de su historia", BBC, Mundo, en <http://www.bbc.com/mundo/noticias/2015/09/150922_volkswagen_escandalo_trampa_perdidas_ac $>$, consultado el 9 de octubre 2015, y $<$ http://www.vw.com. $\mathrm{mx} / \mathrm{es} /$ mundo-volkswagen/volkswagen-instituto.html $>$, consultado el 13 de octubre de 2015 .

${ }^{37}$ Loc. cit.

${ }^{38}$ Loc. cit.

${ }^{39}<$ http://uvl.liverpool.com.mx/home/index.html $>$, consultado el 6 de agosto de 2015 . 
la creación de un portafolio multidisciplinario de programas educativos para formar en cada persona una visión absoluta de participación en diversos sectores profesionales del país [...] el equipo operativo y docente conjuga conceptos como son criterio, visualización y funcionalidad para concebir nuevos programas educativos originados por las demandas competitivas de la actualidad. ${ }^{40}$

Se afirma que su misión consiste en: profesionalizar al personal y sus familiares, satisfacer las necesidades de capacitación especializada de la empresa, generar ingresos mediante la comercialización de programas y servicios, y proveer conocimiento y soluciones aplicables al negocio.

\section{Europa}

En España, la reforma educativa de 2014, la Ley Orgánica para la Mejora de la Calidad Educativa ${ }^{41}$ (LOMCE), cita como sus principales objetivos reducir la deserción temprana de los educandos, mejorar las tasas de desempeño según criterios internacionales, así como aumentar la "empleabilidad y estimular el espíritu emprendedor de los estudiantes". Para estos fines, se eliminaron como obligatorias todas las materias humanísticas, a pesar de la protesta de profesores, intelectuales y filósofos, ${ }^{42}$ como Emilio Lledó, que piensan que con ello "se está dando muerte a la riqueza más grande de un país que es la cultura". ${ }^{43}$ De las humanidades los alumnos aprenden el pensamiento crítico, el valor de la justicia, la belleza y la democracia, y los ayudan a imaginar y crear.

\footnotetext{
${ }^{40}$ Loc. cit.

${ }^{41}<$ www.mecd.gob.es/educacion-mecd/mc/lomce.html>, consultado el 2 de septiembre

42 "Platón expulsado de clase", El País, 5 de octubre de 2015.

${ }^{43}$ Cfr. <http://politica.elpais.com/politica/2015/10/02/actualidad/1443800282_346551. html>, consultado el 10 de octubre de 2015 .
} de 2015. 


\section{El proceso de Bolonia y el espacio europeo de educación superior}

Este proceso se inició en 1999, cuando los ministros de Educación de 29 países $^{44}$ de la Unión Europea y de otras naciones firmaron una declaración conjunta en Bolonia, Italia, con la que dieron origen a un proceso de convergencia llamado Espacio Europeo de Educación Superior (EEES), al que se han adherido otras naciones. También se han añadido diversos comunicados que dan cuenta de los avances del proceso. ${ }^{45} \mathrm{La}$ Declaración de Bolonia expone entre sus objetivos principales la necesidad de:

a) Crear una Europa del conocimiento, capaz de ofrecer a los ciudadanos las competencias y valores necesarios para consolidar el desarrollo social y humano, su enriquecimiento y, movilidad y empleabilidad.

b) Favorecer el desarrollo global del continente, así como el desarrollo de sociedades pacíficas y democráticas. ${ }^{46}$

Para ello propone las siguientes medidas: ${ }^{47}$

1. Adopción de un sistema de títulos fácilmente comprensibles y comparables de los diplomas universitarios, gracias a un suplemento europeo del título.

${ }^{44}$ En 1999 se unieron Alemania, Austria, Bélgica, Bulgaria, Dinamarca, Eslovaquia, Eslovenia, España, Estonia, Finlandia, Francia, Grecia, Hungría, Irlanda, Islandia, Italia, Letonia, Lituania, Luxemburgo, Malta, Noruega, Países Bajos, Polonia, Portugal, Reino Unido, República Checa, Rumania, Suecia, Suiza; en 2001, Croacia, Chipre, Liechtenstein, Turquía; en 2003, Albania, Andorra, Bosnia y Herzegovina, Rusia, Santa Sede, Serbia, República de Macedonia; en 2005, Armenia, Azerbaiyán, Georgia, Moldavia, Ucrania; en 2007, Montenegro; y, desde 2010 Kazajistán. Mónaco y San Marino son los únicos miembros del Consejo de Europa que no han decidido adherirse. Han sido rechazados Israel, Kirguistán, Kosovo y la República Turca del Norte de Chipre.

${ }^{45}$ Comunicados de Praga (2001), Berlín (2003), Bergen (2006), Londres (2007), Lovaina (2009) y la Declaración de Budapest (2010), que puso fin a la primera década del proceso e inició los Objetivos de Educación y Formación 2020 y de Europa 2020.

${ }^{46}$ Juan Antonio Valor Yébenes, "El Espacio Europeo de Educación Superior", en Introducción-Educación, Problemas de la Civilización Contemporánea I, 2012, México, ITAM, pp. 229-235.

${ }^{47}<\mathrm{http}$ //europa.eu/legislation_summaries/education_training_youth/lifelong_learning/ c11088_es.htm>. 
2. Establecimiento de un sistema de dos ciclos seriados. El primero, con una duración mínima de tres años, al término del cual el titulado tendrá la cualificación apropiada para acceder al mercado de trabajo europeo. El segundo ciclo culmina con la obtención de un doctorado.

3. Implantación del sistema de créditos o Sistema Europeo de Transferencia y Acumulación de Créditos (ECTS), a fin de promover la movilidad de los estudiantes.

4. Eliminación de los obstáculos al ejercicio del derecho a la libre circulación de estudiantes y profesores.

5. Impulso a la dimensión europea de la enseñanza, mediante la cooperación entre sus miembros para desarrollar criterios, metodologías y programas de estudio, comparables; así como, programas integrados de estudio y de investigación a fin de garantizar la calidad educativa.

El Proyecto cuenta con el apoyo de políticos y empresarios europeos. Sin embargo, desde el principio hubo críticos que objetan que el Plan Bolonia va a constituirse en una reforma universitaria al servicio de las grandes empresas. La aplicación en etapas del programa ha provocado el aumento de las críticas, a las que desde 2006 se ha sumado la oposición de movimientos constituidos por estudiantes, profesores y asociaciones de profesionistas de toda Europa, sobre todo en Francia, España y Alemania.

Juan Antonio Valor ${ }^{48}$ clasifica las críticas en los siguientes rubros: ${ }^{49}$

1. El proyecto fue adoptado por los gobiernos sin ninguna discusión pública y tampoco se incluyó a los miembros de la comunidad educativa ni a la sociedad.

2. Se sacrifica la vida universitaria por los intereses cambiantes del mercado y de las grandes empresas. El objetivo es convertir a la universidad en un centro de capacitación de grado superior y de formación continua de los trabajadores, sustituyendo las funciones más significativas de la universidad, como la generación y transmisión de conocimientos, la formación crítica y autónoma de los estudiantes. Por eso, el

${ }^{48}$ Juan Antonio Valor Yébenes, filósofo español, actualmente es vicedecano de Estudios de Relaciones Internacionales y de Convergencia Europea.

${ }^{49}$ Loc. cit. 
proyecto habla de "destrezas", "aptitudes" y "competencias", pero no habla de sus contenidos sustantivos. Las Agencias Nacionales de Calidad y Acreditación insisten en esos criterios como requisitos para la obtención de títulos y la evaluación de los profesores.

3. La adaptación a las exigencias de las empresas y del mercado se traduce en un nuevo modelo pedagógico y educativo que no requiere el diálogo profesor-alumno. En esto consiste el Proyecto Tuning (Tuning Educational Structures in Europe), que insiste en fomentar competencias generales, a las que clasifica en instrumentales, interpersonales y sistémicas, entre las que se incluyen: la capacidad para organizar, planificar y para tomar decisiones, la capacidad crítica y autocrítica, el trabajo en equipo, las habilidades interpersonales, la apreciación de la diversidad y multiculturalidad, la habilidad de trabajar en un contexto internacional, la capacidad para adaptarse a nuevas situaciones, creatividad, liderazgo, iniciativa y espíritu emprendedor.

Con esto queda claro que las competencias tienen que ver más con los perfiles que buscan las empresas para contratar a sus empleados y no con los criterios intrínsecos de la docencia y la investigación, ni con la misión esencial de la universidad.

Asia

En esta región destacan dos tendencias inversas, la de China y la de Japón. En China, ${ }^{50}$ con las últimas reformas para la educación de líderes se busca crear ciudadanos con un amplio criterio, capaces de tener ideas independientes y originales. Para esto — piensan-, no sirve su sistema tradicional basado en la memorización. Por ello, la Universidad de Beijing ha desarrollado programas exclusivos para sus estudiantes mejor dotados, a fin de que cursen materias humanísticas, de manera que obtengan las destrezas necesarias para asimilar la nueva información y resolver problemas.

${ }^{50}$ Richard C. Levin, "El mejor de la clase”, Foreign Affairs Latinoamérica, vol 10, núm. 3, 2010, pp. 81-92. 
En sentido contrario, ${ }^{51}$ el ministro de Educación de Japón, Hakuban Shimomura, ${ }^{52}$ solicitó a las 86 universidades nacionales de su país que cerraran sus facultades de ciencias sociales (entre las que están comprendidas Economía, Derecho y Educación), humanidades y bellas artes, como literatura y lenguas, para sustituirlas por carreras que se ajusten a las necesidades de la economía japonesa. Ya 26 universidades confirmaron sus planes para ajustarse a la medida y otras 17 informaron que hacen planes para recortar el número de inscritos a esas carreras. Jack Grove, en el portal The Time Higher Education, dice que las humanidades benefician a los países y su industria, y citó al Consejo Nacional de Ciencias de Japón, que se opone a las reformas por los efectos graves y perniciosos que tendrá la medida en el desarrollo del país. ${ }^{53}$

\section{Crisis social y crisis de la universidad}

Vivimos en un tiempo de grandes transformaciones en todos los órdenes de la vida. En esta coyuntura, se nos abren múltiples posibilidades tanto para edificar un futuro más humano y más justo, como para destruirnos y destruir a nuestro planeta. ¿Cuál se realizará? Eso depende de las decisiones que tomemos desde hoy como individuos y como sociedades.

El historiador mexicano Luis González escribió: "Todo presente da la impresión de ser ruptura del pasado inmediato aun cuando solo es crisis pasajera, pero el de ahora quizá no sea un presente de esos pues presenta cuarteaduras extraordinarias". Y más adelante: "los síntomas permiten pensar que estamos viviendo una crisis tan profunda como las de los siglos XVI y XVII en América". Entre los indicios de tal mutación señala: ${ }^{54}$ 1) Las cada vez menos armoniosas relaciones de los

${ }^{51}$ De acuerdo con la política para reactivar la economía japonesa del primer ministro japonés, Shinzo Abe, que fue reelegido en diciembre de 2012, se hicieron reformas llamadas "abenomía", que incluyen la reforma educativa.

${ }^{52} \mathrm{Cfr}$ < $<\mathrm{http}: / /$ www.elespectador.com/noticias/educacion/japon-quiere-restringir-humanidades-su-reforma-educativ-articulo-588207>, consultado el 21 de octubre de 2015.

${ }^{53} \mathrm{Cfr}$. $<\mathrm{https}$ ://www.timeshighereducation.com/news/humanities-needs-overhaul-stressbenefits-industry>, consultado el 21 de octubre de 2015.

${ }^{54}$ Luis González, "El linaje de la cultura mexicana", Vuelta, núm. 52, 1982. pp. 14-23. 
grupos sociales con la autoridad. 2) El ahondamiento y recrudecimiento de las desigualdades entre pobres y ricos y entre poderosos y débiles. 3) El papel menguante de la familia en el proceso de socialización de las nuevas generaciones. 4) El narcotráfico y la drogadicción. 5) La pérdida del interés en la lectura y el pensamiento abstracto, a pesar de los grandes logros en la alfabetización de las masas. 6) La transformación en los modelos y modos de entretenimiento: la moda ya no se inspira en la burguesía, sino en los sectores marginales de la sociedad; aumenta el culto al cuerpo y a las actividades deportivas; el cine, la tele, los conciertos masivos y los videojuegos son los grandes atractivos. Las artes visuales, que fueron las reinas en la cultura barroca, vuelven a brillar con recursos técnicos muy diferentes a los del pasado. "Las imágenes se mueven y atrapan con mayor facilidad a los mirones y, como siempre, el arte audiovisual ayuda al acercamiento de las clases aristocráticas y populacheras". 55 7) Por último, la historia será una de las disciplinas más irreconocibles en el futuro próximo, porque existe la sensación de estar poco unido con el pasado.

La enumeración que hace González no agota las series de cambios que han transformado a nuestras sociedades. Entre algunos síntomas de la descomposición social que vivimos podemos mencionar las migraciones masivas, los movimientos forzados de personas y los desplazamientos humanos que se han vuelto un fenómeno intensivo y cotidiano. La discriminación, el maltrato y la violencia contra otros seres humanos se extienden y se han vuelto parte de la realidad cotidiana. Pareciera que la vida humana no tiene valor. Tiempos extraños los nuestros en que los activistas defienden más los derechos de los animales o del medio ambiente, pero no los de las personas. Tiempos en que la desigualdad aumenta hasta hacerse intolerable. Cuando tres cuartas partes de la humanidad viven en situación de pobreza, a pesar del crecimiento económico.

Además, tenemos progresos inéditos de las ciencias astrofísicas y de la tierra, así como de la paleontología y la biología, ocurridos en la segunda mitad del siglo XX, que están cambiando las ideas más firmes

\footnotetext{
${ }^{55}$ Loc. cit.
} 
y seguras de la ciencia moderna acerca de la naturaleza, la tierra, la vida y el hombre.

El filósofo español Rubert de Ventós describe así algunas de estas implicaciones:

Deseábamos lo imposible, es cierto, o por lo menos creíamos desearlo. Pero ya de nuestro inmediato pasado nos llegaban dos inquietantes advertencias al respecto. Una decía: vigilad lo que deseáis, porque lo vais a conseguir. Y la otra, la desgracia del hombre jamás proviene del hecho de no ser dueño de su destino; este dominio, por el contrario, lo hará absolutamente desgraciado. Comenzamos apenas a empuñar nuestro destino biológico y lo primero que sentimos es que nos quema la mano. En efecto, muchas cosas estaban desde siempre en manos de Dios. Dios nos daba los hijos y se llevaba a nuestros abuelos; hoy vamos teniendo que decidir el sexo de nuestros hijos o la desconexión de nuestros abuelos, antes que la cura se transforme en tortura. Y ello es así, por mucho que tratemos de sacarnos las pulgas diciendo que sea la Naturaleza, o la Ciencia, o el Especialista, o cualquier otro dios de ocasión [...] La selección natural se transforma en selección artificial. El destino del mundo y de la vida está en nuestras manos. De espectadores pasamos a ser autores; nuestra cosmovisión es ahora cosmo-decisión. Va a cambiar la idea de identidad, de derecho o de humanidad que tenemos. De ahí que convenga discutir acerca de los posibles abusos y anticipar su previsible impacto sobre nuestros usos y creencias, sobre nuestra autopercepción y sobre nuestra moralidad. ${ }^{56}$

Los avances extraordinarios en las telecomunicaciones han creado un nuevo tipo de sociedad, la "sociedad red". ${ }^{57}$ También han producido lo que primero describió el filósofo alemán Arthur Schopenhauer ${ }^{58}$ como el pensamiento que se sostiene a sí mismo, o lo que Marcuse ${ }^{59}$ llamó el pensamiento unidimensional y que Ignacio Ramonet ${ }^{60}$ describe

${ }^{56}$ Xavier Rubert de Ventós, "El azar y la moralidad", El País, 7 de mayo de 1997.

${ }^{57}$ Manuel Castells, "El poder en la era de las redes sociales", Nexos, $1^{\circ}$ de septiembre 2012 , en $<$ http://www.nexos.com.mx/?p=14970>.

${ }^{58}$ Arthur Schopenhauer, El mundo como voluntad y representación, 2005, México, Akal.

${ }^{59}$ Herbert Marcuse, El hombre unidimensional, 1999, Madrid, Ariel.

${ }^{60}$ Ignacio Ramonet, La tiranía de la comunicación, 1998, Madrid, Temas de Debate. 
como pensamiento único, porque exclusivamente se piensa en ganar, y se caracteriza por ser instantáneo, planetario, inmaterial y permanente.

Algunos jóvenes de todo el mundo buscan nuevas alternativas a estas crisis. Entre el 9 y 14 de agosto de 2014, cerca de 150 jóvenes de 24 países de Europa, África, América y Asia se reunieron en la Universidad Humboldt de Berlín para debatir sobre el tema Educación: en camino hacia una nueva civilización, dentro del marco de las actividades de Parlamento Universal de la Juventud de la UNESCO. Ahí firmaron un manifiesto que se llama Magna Charta ${ }^{61}$ y en el que declararon:

Observamos en nuestra sociedad muchos hechos positivos, pero, a la vez, realidades en crisis y que tienen necesariamente que mejorar. Hay carencia y relativización de los valores humanos y trascendentes. Constatamos, con preocupación, que nos movemos por intereses egoístas, por el individualismo, hipocresía, consumismo materialista, culto a la personalidad, popularidad, prestigio social. Consecuentemente, los que gobiernan los estados buscan, casi siempre, sus propios intereses y se corrompen con facilidad; la propia sociedad participa de esta corrupción [...] Sentimos la presión de una educación a la que tenemos que dedicar cada vez más años y que fomenta una excesiva competitividad, genera incertidumbre respecto del futuro laboral, y deja fuera a los que tenemos dificultades o problemas diversos [...] Deseamos formar una nueva civilización de personas que aspiren a tener una vida plena y con un sentido transcendente, que vivan valores y virtudes que dignifican al ser humano. Queremos contribuir a reavivar la esperanza en nuestra sociedad para que se haga posible un mundo fraterno. ${ }^{62}$

Vivimos un momento histórico particular. Por todas partes se percibe un estado de desesperanza, incertidumbre y perplejidad. Vemos a nuestros semejantes con desconfianza, sentimos que son una amenaza y no una promesa en la construcción de nosotros mismos y de la

${ }^{61}$ Magna Charta, Declaración del Parlamento Universal de la Juventud, en $<$ http:// www.wyparliament.org/blog/2014/08/22/manifiesto-puj-berlin-2014/>, consultado el 28 de agosto de 2014.

${ }^{62}$ Loc. cit. 
humanidad. Si la sociedad está en crisis es porque también la universidad lo está.

Cuando la universidad se extravía y pierde su sentido, cuando no busca conservar ese fondo permanente del que habla Marc Bloch, deja de ser luz y brújula.

José Ramón Benito explica así a la crisis actual de la Universidad:

Hoy por hoy el conocimiento se vende en grandes tiendas por departamentos, llamados colegios universitarios o universidades, donde los estudiantes pueden comprar según lo anunciado el tipo de conocimiento que se acomoda a su gusto o satisface sus necesidades para venderse mejor en el mercado laboral [...] Se trata aquí de esa línea de hechos en que aparece la universidad dentro de la perspectiva de la sociedad de consumo [...] la preocupación por la comercialización del saber y sobre todo por su automatización tal y como aparece hoy muestra que lo que está en juego es el ser de nuestra cultura y del hombre mismo. ${ }^{63}$

La exclusión de todo pensamiento no científico nos lleva a una pluralidad de saberes, pero con una imposibilidad de saber. [...] La crisis de la inteligencia nos conduce a perder el misterio del hombre, a la desconfianza mutua a la confusión de la verdad con la sinceridad, de lo importante con lo urgente, porque no hay sentido, ni brújula, ni rumbo. ${ }^{64}$

Carlos de la Isla dice lo siguiente:

La Universidad beneficia mucho más a la sociedad si en vez de emplearse en moldear productos humanos competitivos en el mercado del dinero, se concentra en la formación de hombres capaces de construir un mercado en el que el valor de las personas esté muy por encima del monetario, un mercado que maneje el capital al servicio de todas las personas y de su hábitat. ${ }^{65}$

Una Universidad puede escapar de estas perversiones y complicidades si, y solo si, como se ha dicho, forma en sus estudiantes una clara y fuerte conciencia de responsabilidad social y si ella misma se compromete con la justicia. Hay algunos medios indispensables para la formación de esta

${ }^{63}$ Benito, "Universidad y filosofía", op. cit.

${ }^{64}$ Loc. cit.

${ }^{65}$ De la Isla, "Reflexiones sobre la educación para la invención del futuro". 
conciencia ética en la educación. Por la esencia del quehacer universitario, la evidencia intelectual ha de ser el medio más poderoso. Ningún problema existe para demostrar la dignidad intrínseca de los seres humanos, el derecho que tienen a ser tratados como iguales, el derecho, por el solo hecho de ser personas, de poder disponer de todos los elementos para formular y realizar su proyecto de vida. Los argumentos en favor del bien común, de la justicia conmutativa, distributiva y social son indiscutibles por contundentes con demostraciones del sentido común, de la intuición, de la argumentación inductiva y deductiva, desde los grandes griegos hasta las más recientes teorías éticas de la justicia social. Es obvio, sin embargo, que una cosa es saber qué es la justicia y otra cosa es ser justo; que una cosa es saber qué debemos hacer y otra cosa más difícil es hacer lo que debemos. Por eso las evidencias racionales de la responsabilidad social deben ser tan fuertes que muevan a la acción de la justicia. ${ }^{66}$

De esta manera, la responsabilidad social de la universidad es inherente a ella, además de ser antídoto frente a las desviaciones y perversiones a las que puede ser sometida. La búsqueda de la justicia y la misión fundamental de la universidad están indisolublemente ligadas en su tarea de construir humanidad.

\section{Responsabilidad social de la Universidad}

Las relaciones entre la sociedad y la universidad siempre han sido problemáticas, a veces conflictivas y es sano que lo sean, porque esto es un indicador de que está cumpliendo con su tarea de ser una escuela de humanidad, en la que se enseña al hombre a ser hombre, que crea y difunde la cultura, entendida como el sistema de ideas vivas con las cuales un hombre vive y que, como conciencia crítica, denuncia, anuncia e inventa caminos no solo deseables, sino también posibles, en la tarea siempre inacabada de constituir la comunidad humana en justicia y dignidad. Cuando las universidades cumplen su misión, influyen de manera decisiva en la transformación social; por eso muchos poderes tratan

${ }^{66}$ De la Isla, "Ética y universidad", p. 14. 
de someterlas para dirigir el futuro a su conveniencia. Estas relaciones en la actualidad comprenden políticas educativas del Estado, pero también de desarrollo económico, científico y tecnológico, programas de financiamiento público y privado, vinculaciones con empresas y grandes corporaciones internacionales y otras.

En 1998, la Conferencia Mundial Sobre la Educación Superior de la UNESCO promulgó en París la Declaración Mundial Sobre la Educación Superior en el Siglo XXI: Visión y Acción y el Marco de Acción Prioritaria para el Cambio y el Desarrollo de la Educación Superior. ${ }^{67}$ Estos acuerdos llevaron más de una década de preparación y estudio en conferencias regionales en las que se debatieron los fundamentos y problemas comunes.

En el Preámbulo se subraya que las instituciones de educación superior enfrentarán una demanda sin precedente, tanto por el número de estudiantes como por la diversidad de las carreras. El número de estudiantes inscritos aumentó más de seis veces entre 1960 y 1995, al pasar de 13 millones a 82 millones de alumnos, y la tendencia sigue creciendo. Tristemente, en este mismo periodo la desigualdad se incrementó entre los países y en cada uno. Una de las causas es la inequidad en el acceso a la educación, que afecta a grandes sectores de la población. Por otra parte, se afirma que existe cada vez mayor conciencia acerca de la importancia que tiene la educación en el desarrollo sociocultural y económico para la construcción del futuro de las naciones. Por ello, "las nuevas generaciones deberán estar preparadas con nuevas competencias y nuevos conocimientos e ideales". ${ }^{68}$

Entre los compromisos de esta Declaración son de subrayar los siguientes: ${ }^{69}$

1. Construir un espacio abierto para la formación superior que propicie el aprendizaje permanente y la posibilidad de salir y entrar fácilmente del sistema, brindando oportunidades de movilidad, a fin de formar

${ }^{67} \mathrm{Cfr}$. $<$ http://www.unesco.org/education/educprog/wche/declaration spa.htm>.

${ }^{68}$ Loc. cit.

${ }^{69}$ Xiomara Xarur, "La reflexión sobre la responsabilidad social universitaria (RSU), y su sentido para la educación superior en la sociedad latinoamericana y caribeña”, Educación Superior y Sociedad, Instituto Internacional de la UNESCO para la Educación Superior en América Latina y el Caribe (IESALC), núm. 2, septiembre de 2008, pp. 9-15. 
ciudadanos que participen activamente en la sociedad y estén abiertos al mundo.

2. Contribuir con la protección y consolidación de los valores de la sociedad, en un marco de justicia, de promoción de los derechos humanos, del desarrollo sostenible, de la democracia y de la paz.

3. Proporcionar perspectivas críticas y objetivas para propiciar el debate sobre las opciones estratégicas y fortalecer las perspectivas humanistas a fin de ayudar a la sociedad a erradicar la pobreza, la intolerancia, la violencia, el analfabetismo, el hambre, el deterioro ambiental y las enfermedades, mediante planteamientos interdisciplinarios y transdisciplinarios para analizar los problemas.

4. Apoyar la creación de una nueva sociedad más pacífica y vinculada con el mundo del trabajo y demás actores sociales.

En la Declaración de la Conferencia Regional de Educación Superior realizada en Cartagena de Indias, Colombia, del 3 al 6 de junio de 2008, en el apartado sobre la responsabilidad social de la educación superior en los países de la región destaca el numeral D, ${ }^{70}$ que a la letra dice:

\section{VALORES SOCIALES Y HUMANOS DE LA EDUCACIÓN SUPERIOR}

1. Es preciso hacer cambios profundos en las formas de acceder, construir, producir, transmitir, distribuir y utilizar el conocimiento. Como ha sido planteado por la UNESCO en otras oportunidades, las instituciones de Educación Superior y, en particular, las Universidades tienen la responsabilidad de llevar a cabo la revolución del pensamiento, pues esta es fundamental para acompañar el resto de las transformaciones.

2. Reivindicamos el carácter humanista de la Educación Superior en función del cual ella debe estar orientada a la formación integral de personas, ciudadanos y profesionales, capaces de abordar con responsabilidad ética, social y ambiental los múltiples retos implicados en el desarrollo endógeno y la integración de nuestros países, y participar activa, crítica y constructivamente en la sociedad.

${ }^{70}$ Declaración de la Conferencia Regional de Educación Superior, Cartagena de Indias, Colombia, 2008, en <http://www.oei.es/salactsi/cres.htm>, consultado el 12 de septiembre de 2014. 
3. Es necesario promover el respeto y la defensa de los derechos humanos, incluyendo: el combate contra toda forma de discriminación, opresión y dominación; la lucha por la igualdad, la justicia social, la equidad de género; la defensa y el enriquecimiento de nuestros patrimonios culturales y ambientales; la seguridad y soberanía alimentaria y la erradicación del hambre y la pobreza; el diálogo intercultural con pleno respeto a las identidades; la promoción de una cultura de paz, tanto como la unidad latinoamericana y caribeña y la cooperación con los pueblos del Mundo. Estos forman parte de los compromisos vitales de la Educación Superior y han de expresarse en todos los programas de formación, así como en las prioridades de investigación, extensión y cooperación interinstitucional.

4. La Educación Superior, en todos los ámbitos de su quehacer, debe reafirmar y fortalecer el carácter pluricultural, multiétnico y multilingüe de nuestros países y de nuestra región.

5. Las instituciones de Educación Superior deben avanzar en la configuración de una relación más activa con sus contextos. La calidad está vinculada a la pertinencia y la responsabilidad con el desarrollo sostenible de la sociedad. Ello exige impulsar un modelo académico caracterizado por la indagación de los problemas en sus contextos; la producción y transferencia del valor social de los conocimientos; el trabajo conjunto con las comunidades; una investigación científica, tecnológica, humanística y artística fundada en la definición explícita de problemas a atender, de solución fundamental para el desarrollo del país o la región, y el bienestar de la población; una activa labor de divulgación, vinculada a la creación de conciencia ciudadana sustentada en el respeto a los derechos humanos y la diversidad cultural; un trabajo de extensión que enriquezca la formación, colabore en detectar problemas para la agenda de investigación y cree espacios de acción conjunta con distintos actores sociales, especialmente los más postergados.

6. Es necesario promover mecanismos que permitan, sin menoscabo de la autonomía, la participación de distintos actores sociales en la definición de prioridades y políticas educativas, así como en la evaluación de estas. ${ }^{71}$

${ }^{71}$ Loc. cit. 
Por su parte, François Vallaeys escribe: ${ }^{72}$

En los últimos tiempos se habla mucho de la "responsabilidad social" como una dimensión ética que toda organización o institución debería tener como visión y promover en su actividad diaria. Hace buen tiempo que el mundo empresarial ha acogido y desarrollado la idea, pero la reflexión acerca de la responsabilidad social recién empieza a darse en el ámbito universitario. $^{73}$

Por esto, propone revisar los planteamientos de la responsabilidad social empresarial para que la universidad pueda inspirarse en ella. Pone como ejemplo el Libro verde de la Unión Europea, ${ }^{74}$ que define a la responsabilidad social de la siguiente manera:

El concepto por el cual las empresas deciden contribuir voluntariamente a mejorar la sociedad y a preservar el medio ambiente. A través suyo, las empresas se conciencian del impacto de su acción sobre todos y expresan su compromiso de contribuir al desarrollo económico, a la vez que a la mejora de la calidad de vida de los trabajadores y sus familias, de la comunidad local donde actúan y de la sociedad en su conjunto.

Más adelante, explica que la responsabilidad social presupone la superación de un enfoque egocéntrico. Esta conciencia organizacional trata de ser global e integral (incluye tanto a las personas como al ecosistema, así como a sus trabajadores y clientes), de manera que "contagia" a todas las partes de la organización (todos sus miembros deben poder acceder a ese nivel de conciencia). Se trata de una voluntad ética e interesada en hacer las cosas "bien" para que todos los beneficiarios internos y externos de los servicios de la organización estén "bien”. La ética,

${ }^{72}$ Filósofo peruano, especialista en responsabilidad social universitaria (RSU) y ética aplicada a la gestión de las organizaciones. Es asesor internacional sobre responsabilidad social empresarial y consultor internacional sobre responsabilidad social universitaria. Asesora a varias universidades latinoamericanas, entre las que destaca la Pontificia Universidad Católica del Perú (PUCP, Lima).

${ }^{73}$ François Vallaeys, “¿Qué es la responsabilidad social universitaria?”, en <https://www. url.edu.gt/PortalURL/Archivos/09/Archivos/Responsabilidad_Social_Universitaria.pdf>, consultado el 18 de agosto de 2014.

${ }^{74} \mathrm{Cfr}$. <http://europa.eu.int/comm/off/green/index_es.htm>. 
entonces, no aparece como freno al interés egoísta de la organización, sino al contrario, como empuje para su provecho. Así se crea una articulación pocas veces practicada entre ética y eficacia Con base en esta articulación se definen ciertos principios y valores como parámetros de acción "buena" para la organización, los cuales se incluyen en la estrategia global y el funcionamiento rutinario para que impregnen todos sus ámbitos.

Vallaeys dice que la universidad debe transformarse radicalmente, cambiando su estructura de gestión y sus métodos pedagógicos para convertirse en un agente de desarrollo social. Por eso debe "superar el enfoque de la 'proyección social y extensión universitaria' como 'apéndices' bien intencionados a su función central de formación estudiantil y producción de conocimientos, para poder asumir la verdadera exigencia de la responsabilidad social universitaria". ${ }^{75}$

Después de reconocer que no solo se trata de reformar las malas políticas, sino también "los malos conocimientos y epistemologías que la Universidad contribuye en producir y transmitir". Propone el desarrollo de los "métodos pedagógicos del aprendizaje basado en problemas y el aprendizaje basado en proyectos La meta es promover la investigación para el desarrollo, bajo todas las formas posibles. Por ejemplo, una estrategia posible es que la universidad firme convenios de 'hermanamiento' con otras agencias e instancias gubernamentales y empresariales". ${ }^{76}$

Como se ve, aunque se utilicen las mismas palabras los conceptos se definen en sentido contrario de lo que la universidad ha mantenido como su herencia más significativa: la formación del hombre para hacerlo capaz de dirigir su destino personal y social, frente al desarrollo de destrezas instrumentales para resolver problemas concretos. Se confunde conocimiento (sabiduría) con aprendizaje (capacidades, destrezas y habilidades). Tampoco es cierto que la noción de responsabilidad social universitaria sea nueva. En su sentido original la universidad busca formar hombres libres, pensantes, críticos y comprometidos con

${ }^{75}$ Vallaeys, loc. cit.

${ }^{76}$ Loc. cit. 
su sociedad, su mundo y su historia. Hoy parece que se quiere responder a las necesidades del libre mercado fomentando el éxito y las capacidades competitivas. Por esto la universidad está en crisis. Se busca transformar su esencia, su fondo permanente. El gran riesgo es perder lo que hasta ahora le ha dado solidez e identidad a lo largo de los siglos. La auténtica universidad siempre ha asumido su responsabilidad social con valentía, ha enfrentado a los poderes constituidos y ha mantenido con claridad el objetivo central de su misión, es decir, la defensa de lo humano.

\section{El legado de las universidades latinoamericanas}

Uno de los ejemplos importantes para los países de América Latina se encuentra en la defensa de los derechos indígenas que sostuvieron tanto los egresados universitarios como la Universidad de Salamanca, de la que nuestras primeras universidades son herederas. Los que participaron fueron muchos, solo me referiré a los más conocidos. Uno de los primeros fue fray Antonio de Montesinos, dominico que fue perseguido por sus sermones ${ }^{77}$ del 21 y 28 de diciembre de 1511 en Santo Domingo, entonces capital de La Española, hoy República Dominicana. En ellos denunció el maltrato a los naturales de las Indias Occidentales (los indios taínos). ${ }^{78}$ Ante las acusaciones su superior, fray Pedro de Córdoba, y todos los miembros de la Primera Comunidad de Dominicos de América, continuaron con la defensa de los indígenas porque

${ }^{77}$ Véase $<$ http://jubileo.dominicos.org/kit_upload/file/Jubileo/materiales-2010/Sermon-deAntonio-de-Montesinos-Esquema-1.pdf $>\mathrm{y}<\mathrm{http}$ ://www.dominicos.org/500-sermon-montesino/ sermon>, consultados el 12 de septiembre de 2015.

${ }^{78}$ Llegado el domingo y la hora de predicar, subió al púlpito fray Antón Montesinos y leyó su sermón firmado por todos los miembros de su comunidad, y dijo: "Para daros a conocer estas verdades me he subido aquí yo, que soy la voz de Cristo en el desierto de esta isla [...] Esta voz os dice que todos estáis en pecado mortal y en él vivís y morís por la crueldad y tiranía que usáis con estas inocentes gentes [...] Acaso ¿Éstos no son hombres? ¿No tienen ánimas racionales? ¿No estáis obligados a amarlos como a vosotros mismos? ¿Esto no entendéis? ¿Esto no sentís? ¿Cómo estáis en tanta profundidad de sueño tan letárgico dormidos? Tened por cierto que en el estado en que estáis no os podéis más salvar que los que carecen y no quieren la fe de Jesucristo"; 21 de diciembre de 1511, loc. cit. 
la consideraron un deber de justicia. Fueron amenazados y denunciados por el gobernador Diego Colón ante la Corona. Finalmente, Fernando el Católico promulgó, con su Consejo y en junta de teólogos y juristas, las Leyes de Burgos (1521) ${ }^{79}$ ampliadas por las de Valladolid de $1513 .{ }^{80}$ En estas últimas se confirmaron las primeras, a las que se les agregaron otras formas y medios para proteger a los naturales ante la desobediencia de los conquistadores y encomenderos.

Otro fraile ejemplar fue fray Julián Garcés, dominico formado en Salamanca y primer obispo de Tlaxcala, quien además de proteger a los naturales de su obispado frente a los españoles, defendió la humanidad de los indios en una carta ${ }^{81}$ dirigida al papa en 1536. Las razones expuestas y la firmeza de sus argumentos llevaron a Paulo III a promulgar la Bula Sublimis Deus ${ }^{82}$ (1537), en la que declaró la racionalidad de los indios y su derecho a ejercer su libertad, conservar sus autoridades y, mantener sus propiedades, frente a los intereses de los europeos. Ambos documentos son considerados pioneros en la visión moderna de los derechos humanos.

Toda la escuela de Salamanca trabajó sobre temas teológicos, morales, jurídicos y económicos, y sus reflexiones influyeron de manera decisiva en el pensamiento occidental. Entre sus miembros destacan Domingo de Soto, Luis de Alcalá, Francisco Suárez y Francisco de Vitoria. ${ }^{83}$ Todos ellos, de diversas maneras, analizaron las fuentes y los límites de los poderes civil y eclesiástico. Criticaron las extralimitaciones del papa y del emperador en la evangelización y la conquista y siempre defendieron a los indios.

Vitoria, ${ }^{84}$ además, se preocupó por los derechos de los indios y sostuvo las tesis que llevaron a fundamentar el derecho de gentes. Entre

${ }^{79}$ Antonio Muro Orejón, Lecciones de historia del derecho hispano-indiano, 1989, México, Miguel Ángel Porrúa, pp. 47-56.

${ }^{80}$ Ibid., p. 48.

${ }^{81} \mathrm{Cfr}$. < http://webs.advance.com.ar/pfernando/DocsIglLA/Garces-PauloIII.html>, consultado el 20 de junio de 2014.

${ }^{82}$ Cfr. <http://webs.advance.com.ar/pfernando/DocsIglLA/Paulo3_sublimis.html>, consultado el 20 de junio de 2014.

${ }^{83} \mathrm{Cfr}$. <http://www.philosophica.info/voces/vitoria/Vitoria.html>, consultado el 19 de julio de 2015.

${ }^{84}$ Vitoria, loc. cit. 
sus planteamientos destacan sus afirmaciones acerca de que todos los hombres nacen libres y no esclavos; que por derecho natural nadie es superior a otro; que es mejor renunciar al propio derecho que dañar el del otro; que toda nación tiene derecho a gobernarse a sí misma; que el poder del emperador le es delegado por la comunidad, a la que debe servir, de acuerdo a su naturaleza y que, la evangelización no justificaba la conquista.

El proceso continuó con fray Bartolomé de las Casas, ${ }^{85}$ obispo de Chiapas, quien primero denunció el maltrato y las atrocidades cometidas por los españoles en la conquista de las Antillas en La brevísima relación de la destrucción de las Indias, ${ }^{86}$ en la que pidió la abolición de la encomienda. La defensa de los indios se prolongó más de un siglo, con avances parciales y también retrocesos, porque aunque se expidieron muchas leyes protectoras, se suprimió la encomienda y se tomaron algunas medidas protectoras, que afectaban los intereses económicos y políticos de muchos miembros notables del imperio, los cuales pusieron todos los medios a su alcance para que no se practicaran.

Todos estos frailes eran universitarios y hoy nos siguen inspirando para proteger los derechos de los más débiles. Uno de los momentos más brillantes en la lucha de la universidad por defender los derechos humanos es la Polémica de la Junta de Valladolid (1550-1551), que tuvo lugar en el Colegio de San Gregorio, en Valladolid. Ahí, en presencia del emperador Carlos V, debatieron ${ }^{87}$ Bartolomé de las Casas y Juan Ginés de Sepúlveda, que defendía el derecho de los españoles y la autoridad del rey y del papa para someter a los indios, a los que consideraba inferiores. Finalmente, se concedió la razón a fray Bartolomé. De todos estos debates surgieron las Leyes Nuevas (1542-1543), ${ }^{88}$ la figura del

${ }^{85}$ Fray Bartolomé fue encomendero en Santo Domingo y se convirtió al escuchar los sermones de fray Antón de Montesinos.

${ }^{86}$ De las Casas, Obras completas, 1969, Madrid, BAC.

${ }^{87}$ Cfr. fray Domingo de Soto, "Suma de la polémica de fray Bartolomé de las Casas y Ginés de Sepúlveda por las guerras de conquista", en Bartolomé de las Casas, Obras completas, op. cit.

${ }^{88}$ También llamadas Leyes Nuevas, cuyo título completo es: "Leyes y Ordenanzas nuevamente hechas por su Magestad para la gobernación de las Indias y buen tratamiento y conservación de los Indios: que se han de guarder en el Consejo y Audiencias reales que en 
protector de indios, las Reales Provisiones de 1545, así como otras disposiciones que fueron recopiladas en el Cedulario de Vasco de Puga de $1563^{89}$. Todas estas acciones de los frailes muestran que cuando la universidad es consciente de su misión y cumple con la defensa de lo humano, cuestiona, sugiere e inventa, puede influir en la transformación de su sociedad con paciencia y a largo plazo.

Frente a los que proponen la reforma de la universidad para que se convierta en la instancia capacitadora de los nuevos cuadros de la sociedad global, Carlos de la Isla nos recuerda que la universidad no cumple con su obligación de justicia cuando forma profesionistas, científicos y técnicos muy capaces, que aunque contribuyen al progreso social general, a la hora de evaluar los resultados en términos del reparto de los beneficios se observa que se agranda la desigualdad, porque la gran mayoría de los universitarios pertenecen a sectores más o menos privilegiados. Además, los profesionistas "emplean el beneficio de su educación exclusivamente para su provecho, soslayando y hasta despreciando el compromiso de justicia con aquella parte de la sociedad que invirtió en su educación superior en espera de un beneficio global". ${ }^{90}$

\section{Reflexiones finales}

En el contexto de un presente que tiene cuarteaduras por todos lados y un futuro que es necesario inventar, la responsabilidad social de la universidad es enorme, por esto la universidad debe reinventarse volviendo a sus orígenes, descubriendo ese fondo permanente que le da sentido e identidad. Más que nunca, debe permanecer libre y autónoma a fin de formar hombres libres y responsables, comprometidos con sus sociedades y con la humanidad.

ellas residen: y por todos los otros gobernadores, jueces y personas particulares de ellas", Muro Orejón, op. cit., pp. 57-63.

${ }^{89}$ Cuyo título es: "Provisiones, Cédulas, Instrucciones de su Magestad, Ordenanzas de difuntos y audiencias para la buena expedición de negocios y administración de la justicia y gobernación de esta Nueva España y para el buen tratamiento y conservación de los indios desde el año 1525 hasta el presente 1563", Ibid., pp. 71-76.

${ }^{90}$ De la Isla, "Ética y universidad". 
Me preocupa que en los nuevos postulados de la responsabilidad social de la universidad no se plantee una antropología que explicite que el destino de todo desarrollo es el propio hombre. Esta es la razón por la cual el ITAM primero define su antropología como fundamento de su filosofía institucional — requisito indispensable cuando se busca educar al hombre - , y para tener claridad en lo que hace, ha establecido como inamovibles su filosofía institucional, su misión y sus principios, ${ }^{91}$ que se pueden sintetizar de la siguiente manera:

Filosofía institucional (antropología). Nuestro Instituto se inspira en un concepto que entiende al ser humano como ser libre, como ser social comprometido con la elevación y el progreso humano y como ser llamado por vocación esencial a buscar la verdad y el bien. ${ }^{92}$ Considera que la comunidad del ITAM está constituida por "sus órganos de gobierno y administración, el personal académico, administrativo, técnico y de servicio, y por los alumnos". ${ }^{93}$

Por su naturaleza, se define como una escuela libre y universitaria con los siguientes tres principios básicos como norma de su actividad: ${ }^{94}$ Autonomía, entendida como la autodeterminación en los asuntos de su régimen interno: académico, legal, administrativo y financiero. Libertad de cátedra, medio indispensable para el cumplimiento de sus funciones universitarias. Sentido comunitario, pues aspira a convertirse en una comunidad en su más pleno significado, una casa de estudios de excelencia y libertad académica.

Sus objetivos institucionales ${ }^{95}$ son la formación integral de la persona. Se busca formar hombres y mujeres "capaces de actuar de manera informada, racional, crítica y comprometida en la creación, dirección y orientación de la opinión pública, instituciones y obras y capaces también de crear y difundir conocimientos del más alto nivel ético, científico, tecnológico y profesional que permitan a la sociedad tomar conciencia

${ }^{91}$ Estatuto General del ITAM, México, última reforma 2004, cap. II, art. 6 ${ }^{\text {a }}$ cap. III, art. $7^{\circ}$, I y II, <http://www.itam.mx/es/acerca/mision/mision.php>.

${ }^{92}$ Loc. cit.

${ }^{93}$ Estatuto General del ITAM, cap. I, art. 4.

${ }^{94}$ Loc. cit.

${ }^{95}$ Estatuto General del ITAM, cap. III, art. $7^{\circ}$, I, 1-3. 
de su problemática y contribuyan a su comprensión y solución". ${ }^{96}$ Y, Desarrollo de una sociedad más libre, más justa y más próspera. El ITAM reconoce la obligación que adquiere en el desarrollo de la comunidad en la que actúa, asumiendo su lealtad a México, a sus valores y a sus tradiciones, entendidos como patrimonio colectivo. ${ }^{97}$

Creo, como afirma José Ramón Benito, que la crisis de la Universidad se origina porque ha perdido su universalidad, que le permite integrar y estructurar los distintos saberes alrededor de la búsqueda de sentido del proyecto humano. ${ }^{98}$ Aunque la Universidad es de la sociedad y para la sociedad, el mejor servicio que la Universidad puede darle no es atendiendo a sus demandas sin un análisis crítico que las revise a la luz del proyecto de humanidad.

Creo, como afirma Carlos de la Isla, que la tarea de educar exige "no educar hoy para un presente que antes de terminar el programa ya es pasado. Se ha de educar para el futuro, es decir, para siempre. Y se educa para siempre cuando se logra que el estudiante aprenda el oficio más importante y más dificil, el oficio de ser hombre; cuando se logra que el estudiante se comprometa desde su convicción más profunda con su desarrollo personal, con su sociedad y con su historia". ${ }^{99}$

${ }^{96}$ Loc. cit.

${ }^{97}$ Ibid., Informe de la Comisión de Decisiones del Plan Integral de Desarrollo, febrero 1969 $\mathrm{y}<\mathrm{http}$ //www.itam.mx/es/acerca/mision/mision.php $>$.

${ }^{98}$ José Ramón Benito, "Latinoamérica y la Universidad”, op. cit.

${ }^{99}$ Carlos de la Isla, "Reflexiones sobre la educación para la invención del futuro", en Estudios, 39-40, invierno 1994-Primavera 1995, <http://biblioteca.itam.mx/estudios/estudio/ letras39-40/toc.html>, consultado en junio de 2014. 


\section{DOSSIER}

RESUMEN: "Bernard Lonergan, S.J. (1904-1984) es considerado uno de los más grandes pensadores del siglo XX en el campo filosófico y de la Teología. [...] Su pensamiento continúa vigente a través de muchos educadores e investigadores que se reúnen en torno a importantes universidades en Estados Unidos, Canadá, Australia, México, Colombia y otros países." A pesar de lo anterior, Lonergan no es muy conocido en lengua española. Por ello, los Departamentos Académicos de Lenguas y de Estudios Generales organizaron la presentación del libro de Francisco Galán Vélez: Una metafísica para tiempos posmetafisicos. La propuesta de Bernard Lonergan de una Metametodología. En el evento, cuatro profesores comentaron críticamente la investigación del doctor Galán, al tiempo que resaltaron sobre todo dos aspectos significativos del pensamiento metafísico de Lonergan. El primero de ellos es su relación con la filosofía del lenguaje y la posibilidad de una fecunda confrontación entre Lonergan y Wittgenstein. El segundo es la nueva manera de entender el quehacer metafísico como una labor intersubjetiva e interdisciplinar: la metafísica en tiempos posmetafísicos es una tarea permanente de revisión, crítica e integración de los distintos métodos y saberes de las ciencias.

ABSTRACT: "Bernard Lonergan, S.J. (1904-1984) is recognized as one of the greatest thinkers of the twentieth century in philosophy and Theology... His work remains relevant to educators and researchers in important universities in the United States, Canada, Australia, Mexico, Colombia, etc. Nevertheless, Lonegran is not very well known in the Spanish language. Due to this fact, ITAM's Academic Department of Languages and General Studies organized the presentation of Dr. Francisco Galán Vélez's book, Una metafisica para tiempos posmetafísicos. La propuesta de Bernard Lonergan de una Metametodología. During this event, four professors critically reflected on Dr. Galan's research while highlighting the two most important aspects of Longeran's metaphysical thought. The first aspect is its relationship with the philosophy of language and the possibility of a productive confrontation between Longeran and Wittgenstein. The second one is exploring a new way of understanding metaphysical work as an intersubjective and interdisciplinary task, namely metaphysics in post metaphysical times is a constant task involving revision, criticism, and integration of the diverse scientific methods and knowledge.

${ }^{1} \mathrm{http}$ //www.lonerganlat.org/biografia-lonergan-latinoamerica/ consultado el $7 \mathrm{de}$ septiembre de 2016. 
PALABRAS CLAVE: Lonergan, metafísica, filosofía del lenguaje, teología, metametodología.

KEY WORDS: Lonergan, metaphysics, philosophy of language, theology, metamethodology.

RECEPCIÓN: 26 de abril de 2016.

APROBACIÓN: 10 de agosto de 2016.

Estudios 118, vol. XIV, otoño 2016. 